\title{
Patometria, parâmetros genéticos e reação de progênies de mamoeiro à pinta-preta
}

\author{
Marcelo Vivas (*); Silvaldo Felipe da Silveira; Janieli Maganha Silva Vivas; Messias Gonzaga Pereira \\ Universidade Estadual do Norte Fluminense Darcy Ribeiro, Avenida Alberto Lamego, 2000, Parque Califórnia, 28013-602 Campos \\ dos Goytacazes (RJ), Brasil. \\ (*) Autor Correspondente: mrclvivas@hotmail.com
}

Recebido: 9/dez./2011; Aceito: 2/abr./2012

\begin{abstract}
Resumo
A resistência genética constitui-se em alternativa sustentável para o controle de doenças em culturas agrícolas, sendo esta, no entanto, dependente da avaliação de populações naturais ou tradicionais visando à ampliação da base genética. Este trabalho relata a avaliação fenotípica de 24 progênies de mamoeiro, oriundas de genótipos crioulos, cultivados por pequenos agricultores no sul do Estado do Espírito Santo. Avaliaram-se características associadas à resistência à pinta-preta, importante doença desta cultura, causada pelo fungo Asperisporium caricae. Para fins comparativos, foram incluídas uma variedade resistente ('Maradol') e uma suscetível ('Golden') à pinta-preta. Pelos parâmetros genéticos estimados, concluiu-se que na população estudada há variabilidade genética quanto à resistência à pinta-preta suficiente para indicar a seleção recorrente como método de melhoramento.
\end{abstract}

Palavras-chave: Asperisporium caricae, Carica papaya, herdabilidade, resistência genética, variabilidade genética.

\section{Pathometry, genetic parameters and papaya progenies reaction to black-spot disease}

\section{Abstract}

Genetic resistance is a sustainable alternative to control diseases in crops, being indispensable the enlargement of the genetic base to introduce new resistance genes on developing cultivars. This study reports the phenotypic evaluation of 24 papaya progenies, originated of landraces cultivated for small farmers in south of the Espírito Santo State, Brazil. Characteristics related to the resistance to black-spot disease, induced by the fungi Asperisporium caricae were evaluated. For comparison one genotype resistant ('Maradol') and one susceptible ('Golden') to black-spot disease were included on the study. Based on the genetic parameters estimated, the studied population has genetic variability for resistance to black spot diseases appropriates for use of recurrent selection as crop breeding method.

Key words: Asperisporium caricae, Carica papaya, genetic resistance, genetic variability, herdability.

O mamoeiro (Carica papaya L.) é uma das fruteiras tropicais de maior importância socioeconômica no Brasil e no mundo. Atualmente, o Brasil ocupa a segunda posição mundial em volume de produção e a terceira colocação em área colhida (Agrianual, 2011). Entretanto, para incremento da produção e área planta$\mathrm{da}$, diversos desafios precisam ser superados, principalmente os de natureza fitossanitária. A pinta-preta, causada pelo fungo Asperisporium caricae (Speg.) Maubl., tem sido a principal doença foliar fúngica do mamoeiro no Brasil (Rezende e Martins, 2005).

Embora existam programas de melhoramento em andamento visando à seleção de genótipos resistentes à pinta-preta (VIVAs et al., 2011), a busca de novas fontes de resistência à essa doença é de grande importância para ampliar a base genética. Uma das formas de se ampliar a base genética para fins de melhoramento de plantas é a incorporação de genótipos crioulos ou "landraces". Vários trabalhos relatam o uso de genótipos crioulos em programas de melhoramento para a ampliaçáo da variabilidade genética e selecionar novos fenótipos e fontes de genes visando adaptação, rusticidade e resistência à doenças (Araújo e Nass, 2002; Medeiros et al., 2008). Oliveira et al. (2010) avaliaram a diversidade genética de genótipos locais de mamoeiro do Recôncavo Baiano e concluíram que havia variabilidade genética adicional possível de ser utilizada em programas de melhoramento. No entanto, até o momento, não existem trabalhos caracterizando genótipos crioulos (landraces) de mamoeiro quanto à resistência a doenças no Brasil. 
Neste trabalho, desenvolvido no campo e sob inoculação natural, progênies de meio-irmão de mamoeiros oriundas de genótipos crioulos procedentes do sul do Estado do Espírito Santo foram caracterizadas quanto à resistência à pinta-preta. Inicialmente, foram comparados métodos de avaliação da pinta-preta e de quantificação dos sintomas para discriminação dos genótipos. Em seguida, foram estimados parâmetros genéticos que refletem a variabilidade genética da populaçáo estudada quanto a resistência à pinta-preta.

Durante 2009 e início de 2010, foram coletados frutos de genótipos crioulos de mamoeiro cultivados por pequenos agricultores do sul do Estado do Espírito Santo. As plantas foram escolhidas por não terem sintomas de pinta-preta, tanto nas folhas quanto nos frutos, na ocasião da coleta. Grande parte dos genótipos coletados está presente na região e passou por seleção intuitiva dos agricultores. Não foi possível, até o momento, levantar informaçóes sobre a origem dos materiais coletados. Neste trabalho, os genótipos foram discriminados pela posição geográfica das coletas e pelas suas características morfológicas (dados náo apresentados). Como critério de amostragem, frutos de uma única planta em cada propriedade foram coletados. Os frutos foram colhidos em estágio inicial de maturação (primeiras manchas amareladas) e colocados à sombra, onde permaneceram até completarem a maturação. Após a remoção da sarcarostena das sementes extraídas, sob água corrente em peneira, as sementes foram secas por 8 horas sob sol, acondicionadas em sacos de papel e armazenadas em refrigerador a $10{ }^{\circ} \mathrm{C}$.

Em junho de 2010, instalou-se um experimento em blocos casualizados com seis repetiçôes, no município de Mimoso do Sul (Latitude 21 ${ }^{\circ} 03^{\prime} 52^{\prime \prime}$, Longitude 41'21'59”W), Estado de Espírito Santo. Foram estudadas 24 progênies de mamoeiro (23 oriundas do sul do Espírito Santo e uma proveniente da Bahia) e duas variedades para fins comparativos ('Maradol' - padrão resistente e 'Golden' - padrão suscetível). A unidade experimental constituiu-se de uma planta. Os tratamentos foram dispostos em fileiras simples no espaçamento $2 \times 1,5 \mathrm{~m}$. A adubaçáo foi realizada de acordo com MARIN et al. (1995). Não foi feita inoculação das plantas devido a ocorrência natural da pinta-preta na área experimental. Em março de 2011, realizaram-se as avaliaçóes dos sintomas da pinta-preta. Determinou-se em qual folha surgiram os primeiros sintomas da pinta-preta (FIS); a

Tabela 1. Folhas com os primeiros sintomas da pinta-preta (FIS, unid.), incidência de folhas com sintoma de pinta-preta (IPP, \%) e severidade da pinta-preta em folha estimadas com base nas escalas apresentadas por SANTos FilHo et al. (2007) (SSF, \%), VIVAS et al. (2011) (SV, \%) e Santos e Barreto (2003) (SSB, \%) e avaliadas em genótipos (progênies e testemunhas) de mamoeiro em Mimoso do Sul (ES), em 2011

\begin{tabular}{|c|c|c|c|c|c|}
\hline \multirow{2}{*}{ Genótipos } & \multicolumn{5}{|c|}{ Variáveis } \\
\hline & FIS & IPP & SSF & SV & SSB \\
\hline ‘STA-01' & $3,67 \mathrm{~B}$ & $78,6 \mathrm{~A}$ & $2,8 \mathrm{~A}$ & $1,1 \mathrm{C}$ & $2,5 \mathrm{~B}$ \\
\hline 'STA-02' & $4,17 \mathrm{~A}$ & $77,9 \mathrm{~A}$ & $1,7 \mathrm{~B}$ & $0,5 \mathrm{C}$ & $1,5 \mathrm{~B}$ \\
\hline 'STA-03' & $4,33 \mathrm{~A}$ & $77,6 \mathrm{~A}$ & $1,8 \mathrm{~B}$ & $1,4 \mathrm{~B}$ & $2,5 \mathrm{~B}$ \\
\hline 'STA-04' & $4,33 \mathrm{~A}$ & $78,8 \mathrm{~A}$ & $1,8 \mathrm{~B}$ & $1,0 \mathrm{C}$ & $1,8 \mathrm{~B}$ \\
\hline ‘STA-05’ & $3,83 \mathrm{~B}$ & $78,0 \mathrm{~A}$ & $1,8 \mathrm{~B}$ & $1,0 \mathrm{C}$ & $2,0 \mathrm{~B}$ \\
\hline 'STA-06' & $4,00 \mathrm{~B}$ & $72,3 \mathrm{~A}$ & $2,8 \mathrm{~A}$ & $1,6 \mathrm{~B}$ & $2,7 \mathrm{~B}$ \\
\hline ‘STA-07’ & $3,67 \mathrm{~B}$ & $74,9 \mathrm{~A}$ & $2,8 \mathrm{~A}$ & $1,3 \mathrm{C}$ & $2,0 \mathrm{~B}$ \\
\hline 'STA-08' & $4,67 \mathrm{~A}$ & $72,9 \mathrm{~A}$ & $2,0 \mathrm{~B}$ & $0,5 \mathrm{C}$ & $1,8 \mathrm{~B}$ \\
\hline 'STA-09' & $3,83 \mathrm{~B}$ & $78,0 \mathrm{~A}$ & $2,7 \mathrm{~A}$ & $1,2 \mathrm{C}$ & $2,2 \mathrm{~B}$ \\
\hline 'STA-10’ & $4,50 \mathrm{~A}$ & $78,0 \mathrm{~A}$ & $2,8 \mathrm{~A}$ & $1,6 \mathrm{~B}$ & $2,2 \mathrm{~B}$ \\
\hline 'STA-11' & $4,33 \mathrm{~A}$ & $77,5 \mathrm{~A}$ & $2,5 \mathrm{~A}$ & $1,1 \mathrm{C}$ & $2,7 \mathrm{~B}$ \\
\hline 'STA-12' & $4,17 \mathrm{~A}$ & $71,9 \mathrm{~A}$ & $2,8 \mathrm{~A}$ & $1,2 \mathrm{C}$ & $1,8 \mathrm{~B}$ \\
\hline 'STA-13’ & $4,67 \mathrm{~A}$ & $78,2 \mathrm{~A}$ & $1,7 \mathrm{~B}$ & $0,4 \mathrm{C}$ & $1,7 \mathrm{~B}$ \\
\hline 'STA-14’ & $3,50 \mathrm{~B}$ & $74,9 \mathrm{~A}$ & $2,7 \mathrm{~A}$ & $1,1 \mathrm{C}$ & $2,8 \mathrm{~B}$ \\
\hline 'STA-15’ & $4,17 \mathrm{~A}$ & $76,0 \mathrm{~A}$ & $2,2 \mathrm{~B}$ & $0,9 C$ & $2,0 \mathrm{~B}$ \\
\hline 'STA-16' & $5,33 \mathrm{~A}$ & $75,0 \mathrm{~A}$ & $1,8 \mathrm{~B}$ & $0,6 \mathrm{C}$ & $1,8 \mathrm{~B}$ \\
\hline 'STA-17’ & $4,00 \mathrm{~B}$ & $79,9 \mathrm{~A}$ & $1,0 \mathrm{~B}$ & $0,1 C$ & $1,8 \mathrm{~B}$ \\
\hline 'STA-18’ & $4,00 \mathrm{~B}$ & $77,1 \mathrm{~A}$ & $2,2 \mathrm{~B}$ & $1,1 \mathrm{C}$ & $2,2 \mathrm{~B}$ \\
\hline 'STA-19' & $3,33 \mathrm{~B}$ & $77,0 \mathrm{~A}$ & $2,7 \mathrm{~A}$ & $1,8 \mathrm{~B}$ & $2,5 \mathrm{~B}$ \\
\hline 'STA-20’ & $3,33 \mathrm{~B}$ & $78,4 \mathrm{~A}$ & $2,8 \mathrm{~A}$ & $1,8 \mathrm{~B}$ & $2,2 \mathrm{~B}$ \\
\hline 'STA-21' & $3,83 \mathrm{~B}$ & $77,4 \mathrm{~A}$ & $2,3 \mathrm{~A}$ & $1,8 \mathrm{~B}$ & $2,5 \mathrm{~B}$ \\
\hline 'STA-22' & $4,33 \mathrm{~A}$ & $78,2 \mathrm{~A}$ & $2,5 \mathrm{~A}$ & $0,8 \mathrm{C}$ & $1,8 \mathrm{~B}$ \\
\hline 'STA-23' & $3,67 \mathrm{~B}$ & $77,2 \mathrm{~A}$ & $2,7 \mathrm{~A}$ & $1,7 \quad B$ & $2,8 \mathrm{~B}$ \\
\hline 'STA-24' & $4,67 \mathrm{~A}$ & $76,1 \mathrm{~A}$ & $2,3 \mathrm{~A}$ & $0,6 \mathrm{C}$ & $2,2 \mathrm{~B}$ \\
\hline ‘Maradol' & $4,83 \mathrm{~A}$ & $69,5 \mathrm{~A}$ & $1,8 \mathrm{~B}$ & $0,4 \mathrm{C}$ & $1,3 \mathrm{~B}$ \\
\hline ‘Golden' & $3,50 \mathrm{~B}$ & $77,1 \mathrm{~A}$ & $3,0 \mathrm{~A}$ & $3,3 \mathrm{~A}$ & $4,5 \mathrm{~A}$ \\
\hline
\end{tabular}

Médias seguidas de mesma letra na coluna não diferem entre si pelo teste de Scott-Knot $(\mathrm{p}=0,05)$. 
incidência de folhas com sintoma da pinta-preta (IPP) e a severidade da pinta-preta na folha com a primeira flor aberta com base em três metodologias: escala apresentada por SANTos Filho et al. (2007) (SSF), escala apresentada por VIVAS et al. (2011) (SV) e escala proposta por SANTOS e Barreto (2003) (SSB). Para se estimar o valor de FIS, contou-se do ápice para a base qual folha estava com os primeiros sintomas da doença, considerando-se como primeira folha a mais jovem e totalmente expandida (folhas cujo lóbulo central tinha comprimento igual ou inferior ao comprimento do pecíolo). A IPP (\%) foi obtida relacionando-se o número de folhas com sintoma da pinta-preta e o número total de folhas por planta.

Para a análise de variância, comparação dos métodos de avaliação e estimação dos parâmetros genéticos, utilizou-se o programa Genes (Cruz, 2006). As médias dos genótipos (progênies e testemunhas) foram comparadas pelo método de agrupamento Scott-Knott a 5\% de probabilidade. Para cada característica e considerando apenas as progênies, foram estimados os parâmetros genéticos: a) Variância fenotípica média; b) Variância ambiental média; c) Componente quadrático que expressa a variabilidade genética média; d) Coeficiente de determinação genotípico, com base na média de genótipos; e) Correlação intraclasse; f) Coeficiente de variação genético e g) Índice de variação (Cruz e Carneiro, 2003). Considerando que as famílias foram escolhidas na populaçáo com base em seu potencial para resistência à pinta-preta $\mathrm{e}$, portanto, não constituem uma amostra aleatória da população, optou-se por considerar a fonte de variação genótipo como fixa. Assim, não houve variância genética e sim variabilidade genética, o que não impediu que fossem estimados os parâmetros para a populaçáo na qual se pretendia trabalhar.

Houve diferença significativa entre genótipos para as variáveis FIS, SSF, SV e SSB (Tabela 1). Este fato indica a possível existência de variabilidade genética entre os genótipos crioulos avaliados com base nas variáveis avaliadas possibilitando, assim, a seleção de genótipos com menor intensidade da pinta-preta.

Embora tenha ocorrido variabilidade genética (Tabela 1), não foi possível identificar progênies sem sintomas da pinta-preta. Duas hipóteses podem ser aventadas a partir desse resultado: (a) as plantas matrizes não eram resistentes e, consequentemente, as progênies também não foram e (b) os genitores eram resistentes, mas por se tratar de progênies derivadas de famílias de meios irmãos, as progênies tinham nível considerável de variabilidade e a característica pode ter herança poligênica.

Para a característica FIS, observaram-se diferenças significativas para genótipo, o que evidencia variabilidade nas progênies avaliadas. Observou-se a formação de dois grupos constituídos pelos genótipos em que havia as maiores médias de FIS, os quais foram: 'STA-02', 'STA03', 'STA-04', 'STA-08', STA-10', 'STA-11', 'STA-12',
'STA-13', 'STA-15', 'STA-16', 'STA-22', 'STA-24' e 'Maradol' (Tabela 1). Dessas progênies, os primeiros sintomas da pinta-preta foram observados nas folhas abaixo da folha cinco das plantas da progênie 'STA-16', enquanto nas demais progênies, os sintomas da doença iniciaram-se entre a folha quatro e cinco (progênies menos suscetíveis) ou entre a folha três e a folha quatro (progênies mais suscetíveis).

Para a variável IPP, não houve diferença significativa entre os genótipos, e a média variou de 79,9 (progênie 'STA-17') a 71,9 (progênie 'STA-12') (Tabela 1). Quanto à severidade, observou-se que todos os métodos utilizados foram eficientes para discriminar os genótipos quanto à resistência à pinta-preta. Entretanto, observou-se que o método SV foi o mais eficiente, pois possibilitou que os genótipos testados fossem divididos em três grupos. No grupo suscetível, ficou alocada a testemunha 'Golden' e no grupo resistente 17 progênies, além do genótipo 'Maradol' (Tabela 1). Destas, 'STA-02', 'STA-13'e 'STA17 ' obtiveram, numericamente, médias inferiores à média da testemunha resistente.

Para a severidade da pinta-preta estimada com base no método SSB, houve discriminação de dois grupos, sendo a testemunha 'Golden' no grupo suscetível (Tabela 1). Por outro lado, a estimativa da severidade com base na escala SSF, demonstrou que em 11 progênies derivadas de genótipos crioulos a média de severidade foi inferior à média da testemunha suscetível, havendo, assim, a formação de dois grupos (Tabela 1). Das 11 progênies do grupo resistente, 'STA-02', 'STA-13' e 'STA-17' obtiveram, numericamente, médias de severidade inferiores à média do genótipo-padrão resistente 'Maradol'.

Os resultados indicam a possibilidade de seleção de progênies, derivadas de genótipos crioulos, com potencial para a seleçáo de uma população com menor intensidade da pinta-preta. Oliveira et al. (2010) avaliaram

Tabela 2. Estimativas de parâmetros genéticos associados à quantidade de folhas com os primeiros sintomas da pinta-preta (FIS, unid.) e severidade da pinta-preta em folha estimada com base nas escalas apresentadas por SANTOS Filho et al. (2007) (SSF, \%), Vivas et al. (2011) (SV, \%) e Santos e Barreto (2003) (SSB, \%), avaliados em 24 progênies crioulas de mamoeiro em Mimoso do Sul (ES), em 2011

\begin{tabular}{lrrrr} 
& \multicolumn{4}{c}{ Estimativas dos parâmetros } \\
\cline { 2 - 5 } Parâmetros genéticos & FIS & SSF & \multicolumn{1}{c}{ SV } & SSB \\
\hline Variância fenotípica & 0,23 & 0,25 & 0,23 & 0,14 \\
Variância ambiental & 0,13 & 0,08 & 0,14 & 0,14 \\
\hline Variabilidade genotípica média & 0,10 & 0,18 & 0,09 & 0,01 \\
\hline Coeficiente de determinação & 41,79 & 69,51 & 39,12 & 3,81 \\
genotípico & 10,69 & 27,53 & 9,67 & 0,66 \\
\hline Correlação intraclasse & 7,51 & 18,18 & 27,71 & 3,40 \\
\hline CVg & 0,35 & 0,62 & 0,32 & 0,08 \\
\hline Razão CVg/CVe & & & & \\
\hline
\end{tabular}

CVg: coeficiente de variação genético. CVe: coeficiente de variaçẫo experimental. 
por marcadores microsatélite a variabilidade genética de "landraces" cultivadas por pequenos agricultores do Recôncavo Baiano e concluíram que esta pode ser usada em programas de melhoramento do mamoeiro para enriquecimento de populaçóes melhoradas por seleçáo. No entanto, o conhecimento prévio das estimativas de alguns parâmetros genéticos deve ser considerado na escolha do método de seleção a ser adotado em função da característica de interesse.

No presente estudo, observou-se variabilidade para as características FIS, SV, SSF e SSB (Tabela 2). Para SSF, observou-se que a variância genotípica foi maior do que a variância ambiental, sendo, portanto de maior poder discriminante. Nas variáveis FIS e SV também se observaram valores de variância genética altos em comparaçâo com a SSB (Tabela 2). Conclui-se, assim, a possibilidade de selecionar novas progênies para a constituição de futuras populaçóes, devendo-se atentar para o método de seleção a ser utilizado, uma vez que as estimativas de coeficiente de determinação genotípico não foram táo elevadas para algumas variáveis. Com base nos parâmetros genéticos obtidos, a seleção recorrente pode ser utilizada como método de melhoramento, no avanço de geraçóes e desenvolvimento de novas linhagens de mamoeiro, com maior resistência à pinta-preta.

As progênies 'STA-02', 'STA-04', 'STA-08', 'STA-13', 'STA-15' e 'STA-16' são promissoras pelas características que lhes conferem, simultaneamente, redução da severidade da pinta-preta em folhas de mamoeiro. Constatou-se ainda, nas condições deste estudo, que as variáveis IPP e SSB não foram discriminatórias da resistência das progênies de mamoeiro à pinta-preta, tendo-se em vista que tinham pouca ou nenhuma variância genética e houve forte efeito ambiental.

\section{AGRADECIMENTOS}

À Fundação de Amparo à Pesquisa do Estado do Rio de Janeiro (FAPERJ) e à Universidade Estadual do Norte Fluminense Darcy Ribeiro (UENF) pelo suporte financeiro e logístico.

\section{REFERÊNCIAS}

AGRIANUAL 2011: Anuário da agricultura brasileira: Mamão. São Paulo: FNP, Consultoria e Agroinformativos, 2011. p.325-332.

ARAÚJO, P.M.; NASS, L.L. Caracterização e avaliação de populações de milho crioulo. Scientia Agricola, v.59, p.589-593, 2002.

CRUZ, C.D.; CARNEIRO. P.C.S. Modelos biométricos aplicados ao melhoramento genético. Viçosa: Editora UFV, 2003. 585p.

CRUZ, C.D. Programa Genes: biometria. Viçosa: Editora UFV, 2006. 377p.

MARIN, S.L.D.; GOMES, J.A.; SALGADO, J.S.; MARTINS, D.S.; FULLIN, E.A. Recomendaçóes para a cultura do mamoeiro dos grupos Solo e Formosa no Estado do Espírito Santo. Vitória: EMCAPA, 1995. 57p. (Circular Técnica, 3)

MEDEIROS, L.A.M.; BALARDIN, R.S.; COSTA, I.F.D.; GULART, C.A.; LENZ, G. Reação de germoplasma crioulo de feijoeiro (Phaseolus vulgaris L.) a Colletotrichum lindemuthianum. Tropical Plant Pathology, v.33, p.273-280, 2008.

OLIVEIRA, E.J.; AMORIM, V.B.O.; MATOS, E.L.S.; COSTA, J.L.; CASTELLEN, M.S.; PÁDUA, J.G.; DANTAS, J.L.L. Polymorphism of microsatellite markers in papaya (Carica papaya L.). Plant Molecular Biology Reporter, v.28, p.519-530, 2010.

REZENDE, J.A.M.; MARTINS, M.C. Doenças do mamoeiro (Carica papaya L.). In: KIMATI, H.; AMORIM, L.; REZENDE, J.A.M.; BERGAMIN FILHO, A.; CAMARGO, L.E.A. (Ed.). Manual de Fitopatologia: Doenças das Plantas Cultivadas. São Paulo: Agronômica Ceres, 2005. p.435-443.

SANTOS FILHO, H.P.; OLIVEIRA, A.A.R.; NORONHA, A.C.S.; SANCHES, N.F.; LOPES, F.F.; ANDRADE, P.R.O.; OSÓRIO, A.C.B.; SOUZA, J.A.; OLIVEIRA, A.M.G.; SANTOS, M.J. Monitoramento e controle da pinta-preta do mamoeiro. Cruz das Almas: Embrapa, 2007. 5p. (Comunicado técnico 125)

SANTOS, M.C.; BARRETO, M. Estudo epidemiológico da varíola do mamoeiro em cultivares submetidos a tratamento com fungicidas. Summa Phytopathologica, v.29, p.141-146, 2003.

VIVAS, M.; SILVEIRA, S.F.; TERRA, C.E.P.S.; PEREIRA, M.G. Testers for combining ability and selection of papaya hybrids resistant to fungal diseases. Crop Breeding and Applied Biotechnology, v.11, p.36-42, 2011. 